FRI-001.002

Formal Operations is

Reference

Information

LA-UR-93-3760 (Revised)

\title{
Glossary of Formal Operations
}

prepared by the

Configuration Management Office

January 5, 1994

\section{DISCLAIMER}

This report was prepared as an account of work sponsored by an agency of the United States Government. Neither the United States Government nor any agency thereof, nor any of their employees, makes any warranty, express or implied, or assumes any legal liability or responsibility for the accuracy, completeness, or usefulness of any information, apparatus, product, or process disclosed, or represents that its use would not infringe privately owned rights. Reference herein to any specific commercial product, process, or service by trade name, trademark, manufacturer, or otherwise does not necessarily constitute or imply its endorsement, recommendation, or favoring by the United States Government or any agency thereof. The views and opinions of authors expressed herein do not necessarily state or reflect those of the United States Government or any agency thereof. 
This document was produced by the Los Alamos Configuration Management Office.

Authors:

Gary Cort

Steve Donahue

Joe Frank

Brad Perkins

Jon Wrye

Editing:

Alison Caughran

Geana Garrett

Design Credit:

Gloria Sharp

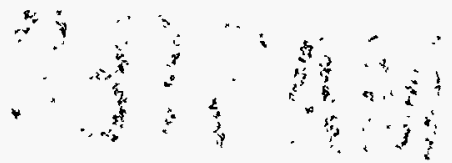




\section{DISCLAIMER}

Portions of this document may be illegible in electronic image products. Images are produced from the best available original document. 


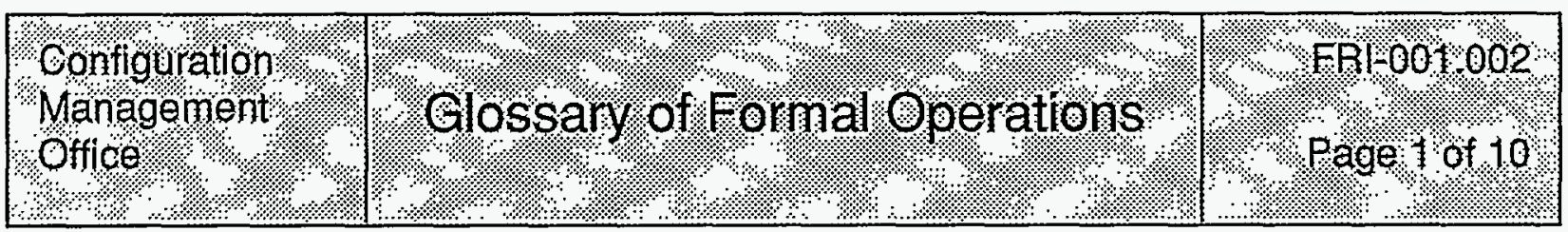

\subsection{PURPOSE}

The purpose of this document is to establish definitions for the terms used in the planning, development, and implementation of a formal operations program at Los Alamos National Laboratory.

\subsection{DEFINITIONS}

acceptance plan. An acceptance plan is a program plan that specifies the criteria for accepting procured items or services. For procured items, an acceptance plan is implemented as either an inspection plan or a test plan. For procured services, an acceptance plan is implemented as an assessment plan.

advocate. An advocate is an individual or work function that identifies a process in need of improvement, suggests improvement strategies, and works with management to implement the improvement.

analyzed change request. An analyzed change request is a change request that the configuration control board has analyzed to determine its merit and expected impact, and has amended as it deems necessary.

analyzed variance request. An analyzed variance request is a variance request that the configuration control board has analyzed to determine its merit and expected impact, and has amended as it deems necessary.

assessment. An assessment is an evaluation that measures the performance of a program, process, system, or facility.

assessment checklist. An assessment checklist is a record used by an assessor to assist in measuring the performance of a program, process, system, or facility. An assessment checklist includes 1) the identifier of the associated assessment plan, 2) the date of the assessment, and 3) a list of assessment criteria.

assessment plan. An assessment plan is a program plan that characterizes an assessment program. The assessment plan specifies the scope of the assessment, the objective criteria that will be used to evaluate the elements in the assessment scope, and one or more assessment checklists.

assessment report. An assessment report is a record that documents the results of an assessment. An assessment report includes 1) the purpose of the assessment, 2) the assessment dates, 3) a list of assessment team members, 4) references to the assessment plan, procedures, and checklists, 5) a summary of assessment activities, 6) a list of assessment findings and observations, and 7) a schedule of follow-up assessments or measurements, if any, that will be required.

assessment sponsor. An assessment sponsor is an individual or work function that requests an assessment and assumes responsibility for planning and implementing the assessment activity.

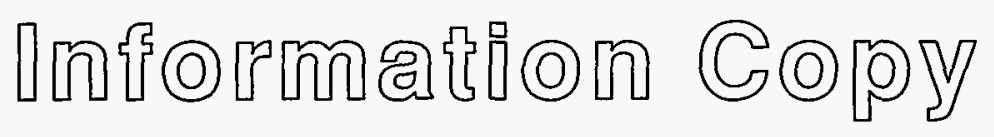




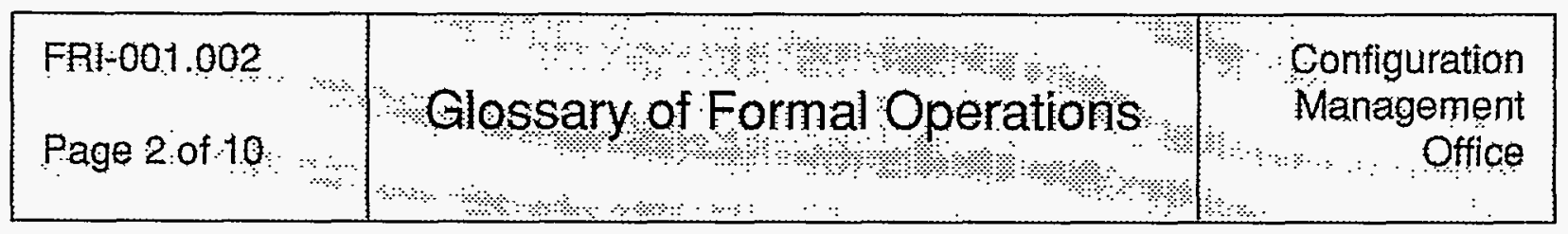

assessor. An assessor is a person or work function responsible for performing an assessment.

authentication. An authentication is a confirmation of the authenticity of a record. It consists of an authorized signature and the date signed.

baseline. A baseline is a collection of functionally related controlled elements referenced to a designated point in time. A baseline reflects the structure of an associated configuration definition and is maintained under configuration management as a unit.

baseline catalog. A baseline catalog is a register of certified baselines that includes the identifier, certification date, title, storage location, and accountable line manager for each certified baseline.

baseline certification. The baseline certification is a record that includes 1) the name of the certified baseline, 2) its identifier, and 3) the certification date.

baseline repository. A baseline repository is an area in which a configuration manager stores certified baseline documents. A baseline repository provides adequate physical storage, security, protection, and retrievability for certified baseline documents.

candidate for qualification. A candidate for qualification is an individual whose qualifications to perform a specific work process are being evaluated by the work process owner.

change agent. A change agent is an individual or work function that has been assigned to implement a change specified in a work authorization.

change request. A change request is a record that characterizes a requested change to an existing baseline or requests creation of a new baseline. A change request includes 1 ) the name of the change requester, 2) a description of the requested change, 3) an indication of urgency, 4) justification for the change, and 5) the configuration-identification labels and descriptions of affected baselines and controlled elements.

change request documentation. Change request documentation is a record that includes the analyzed change request, documentation from the configuration control board's analysis of the change request, disposition of the analyzed change request, and the configuration control board authentication.

change requester. A change requester is an individual or work function that submits a change request.

configuration control board. A configuration control board is a body consisting of one or more individuals or work functions authorized by an accountable line manager to analyze proposed changes, evaluate change implementations, and specify their disposition. The accountable line manager will establish and operate one or more configuration control boards and will document the scope, authority, and reporting structure of each.

configuration definition. A configuration definition is a document that specifies the strategy for grouping related controlled elements into baselines. A configuration definition includes

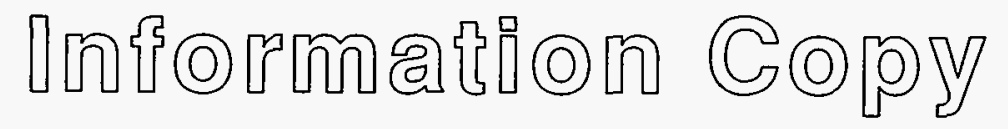




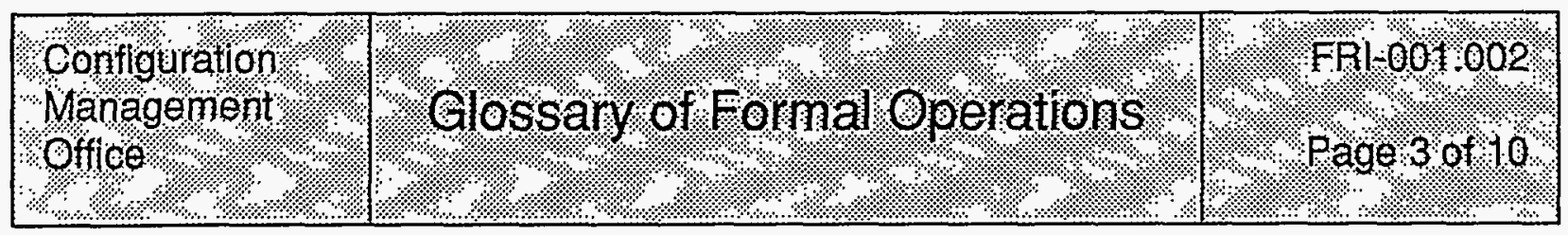

1) a configuration-definition name, 2) a unique identifier, 3) a description of the types of controlled elements included in the configuration definition, 4) a labeling strategy, and 5) a list of related configuration definitions.

configuration management. Configuration management is the discipline of identifying the configurations of controlled elements at discrete points in time for the purposes of systematically controlling changes to the configurations and maintaining the integrity and traceability of the configurations throughout the controlled elements' life cycles. (See page 20 of Reference 2 in Section 3.0.)

configuration management liaison. A configuration management liaison is an individual or work function designated by the accountable line manager to serve as an interface between change requesters or variance requesters and the appropriate configuration control board, and to accept configuration status report requests.

configuration manager. A configuration manager is an individual or work function designated to act as the accountable line manager's agent in configuration management tasks.

configuration status report. A configuration status report is a record that conveys the contents and status of certified baselines, describes the conduct of the configuration management process, or documents process performance.

controlled distribution list. A controlled distribution list is a record that lists the document custodians of controlled copies of a master document. A controlled distribution list includes 1) the identifier of the master document, 2) a list of controlled copy numbers, and 3) the name and address of each document custodian.

controlled distribution request. A controlled distribution request is a record that is submitted to the document manager to request distribution of controlled copies of a master document. A controlled distribution request includes 1) the identifier of the master document, 2) the required number of controlled copies, and 3) the name and address of each document custodian.

controlled element. A controlled element is any information, process, or physical item that is subject to configuration management, and therefore to which the formal operations program applies.

corrective action plan. A corrective action plan is a program plan that specifies how an organization will address a deficiency, occurrence, or nonconformance.

deficiency. A deficiency is a condition of noncompliance with a specified requirement.

deficiency report. A deficiency report is a record submitted to a work process owner that characterizes a deficiency identified in a work process. A deficiency report includes 1) a description of the deficient condition, 2) a reference to affected programs or work processes, 3) an indication of severity, and 4) a description of special conditions or restrictions imposed on the affected programs or work processes.

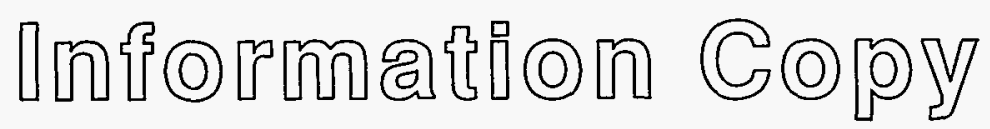




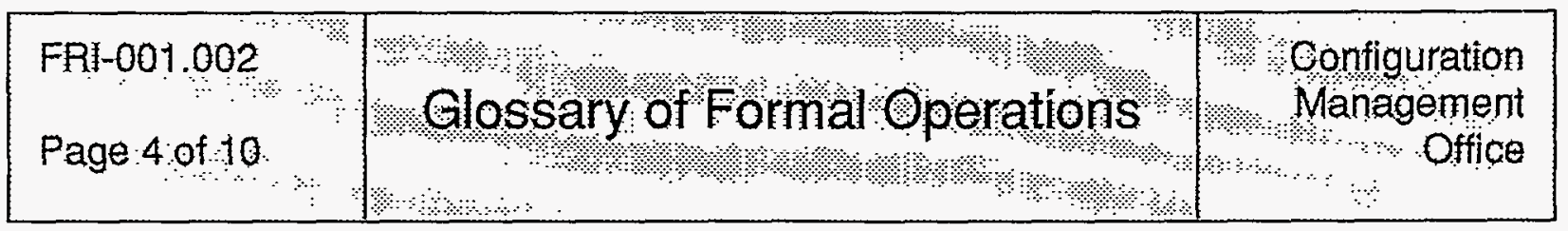

design owner. A design owner is an individual or work function that ensures that a design or design modification meets all applicable specifications and standards.

design plan. A design plan is a program plan that, for a particular design or design modification, includes 1) the applicable design basis, 2) the requirements imposed on the design or modification, 3) the governing specifications, 4) the applicable standards, 5) required design records, 6) special validation criteria, and 7) the affected interfaces.

document. A document is any written or pictorial information describing, defining, specifying, reporting, or certifying activities, requirements, procedures, or results. A document consists of the following elements: 1) a unique identifier, 2) date, and 3) documentspecific contents.

document catalog. A document catalog is a register of master documents that are currently in controlled distribution.

document control standards. Document control standards are requirements that specify the distinct document types supported, the level of security and protection required for each master document, availability criteria, minimum controlled lifetime, and disposal criteria for each document type. Document control standards are specified in a document.

document custodian. A document custodian is an authorized recipient of a controlled copy of a master document.

document distribution package. A document distribution package is a set of documents distributed to a document custodian that consists of 1) the controlled copy of the master document and 2) instructions for incorporating the controlled copy into the work environment, for disposing of superseded versions, and for notifying the document manager of compliance with these instructions.

document improvement questionnaire. A document improvement questionnaire is a form used to gather metrics for assessing the performance of a document.

document manager. A document manager is an individual or work function authorized to admit a candidate master document into the document control environment and to distribute controlled copies of a master document.

document repository. A document repository is an area in which a document manager stores master documents. A document repository provides adequate physical storage, security, protection, and availability for master documents.

evaluation issue. An evaluation issue documents a deficiency identified during a configuration control board evaluation (such as an evaluation of a proposed baseline).

Evaluation issues are documented in records that include 1) the name and /or identification of the proposed baseline, 2) the name and identifier of the controlled element against which the issue is logged, 3) a description of each issue, 4) the location of the issue within the designated controlled element, 5) the name of the evaluator who raised the issue, 6) the identifier of the controlling work authorization, and 7) how the issue was resolved.

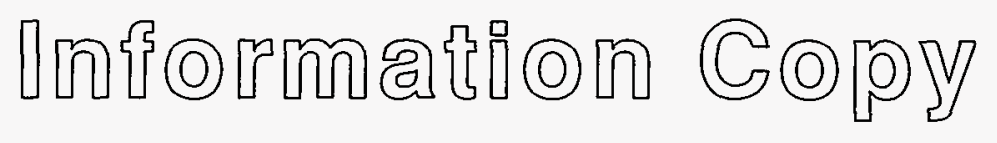




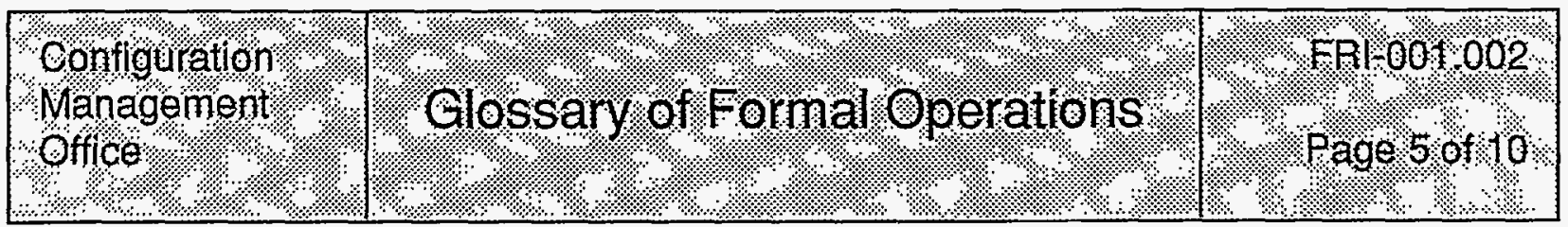

experience documentation. Experience documentation is a record that documents process improvement experience and includes descriptions of the 1) problems identified, 2) strategies utilized, 3) principles and precepts established, 4) results obtained, and 5) lessons learned as a consequence of the process-improvement effort.

finding. A finding is documentation of noncompliance with a specified requirement. The contents of a finding include 1) the identifier of the associated assessment plan, 2) the date of the assessment, 3 ) the name and identifier of the item, program, process, system, or facility against which the finding is logged, 4) a description of the noncompliance (including a reference to the associated requirement), and 5) the name of the assessor that logged the finding.

formal operations element. Any of the disciplines specified in the integrated formal operations plan (e.g., configuration management, document control, and records management).

impact. As used in the context of a graded approach to formal operations, impact is a graded characteristic of an activity that involves controlled elements. A proposed activity is assigned an impact level commensurate with the degree of risk associated with the activity. The assigned impact level characterizes the scope of the activity and the ramifications to the controlled elements of performing the activity.

impact analysis report. An impact analysis report is a record that characterizes the impact of a nonconformance, deficiency, or occurrence on other items, work processes, the environment, safety, and health. An impact analysis report also characterizes the validity and root cause of a nonconformance, deficiency, or occurrence.

importance. As used in the context of a graded approach to formal operations, importance is a graded characteristic of a controlled element. A controlled element is assigned an importance level commensurate with the degree of risk inherently associated with the element. The assigned importance level characterizes the controlled element's relative role in supporting the facility's mission and keeping the facility safe and environmentally benign.

initiator. An initiator is the individual or work function that formally brings deficiencies and occurrences to the attention of management.

inspection plan. An inspection plan is a program plan that includes 1) the purpose of the inspection, 2) the items to be inspected, 3) inspection criteria, 4) a description of sampling methodologies to be used, and 5) applicable calibration criteria.

inspection/test certification documentation. Inspection/test certification documentation is a record that includes 1 ) information that identifies the inspected or tested items, 2) the results of any measurements performed, 3) the date and time of the inspection or test, 4) a reference to the governing inspection or test plan and associated procedures, and 5) the name of the verifier.

inspection/test sponsor. An inspection/test sponsor is an individual or work function that requests an inspection or testing activity and that assumes responsibility for the planning and implementation of the inspection or test.

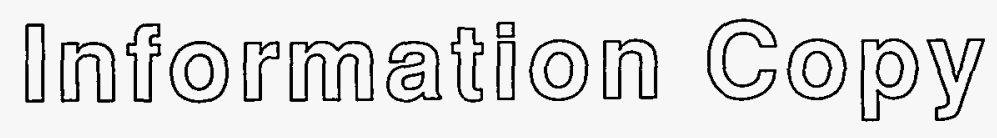




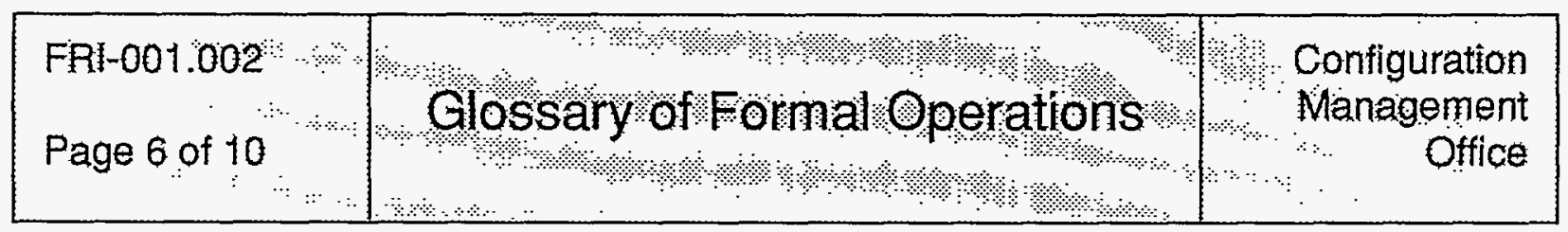

intensity. As used in the context of a graded approach to formal operations, intensity is a graded characteristic of the formal operations process as it is applied to activities involving controlled elements. An intensity level is assigned based on the combination of the impact level of the proposed activity and the importance level of the controlled element involved. The assigned intensity level characterizes the level of formal operations that is necessary to ensure that the activity is performed in a manner that is safe, environmentally benign, and supportive of the overall mission of the facility.

investigator. An investigator is an individual or work function that uses documented plans and procedures, accepted standards and criteria, worker input, and objective measurements to analyze the validity and impact of, determine the root cause of, and develop a corrective action plan for a reported deficiency or occurrence.

lessons learned. Lessons learned is documentation of past experience that is used to optimize current or future programs or work processes.

lessons learned documentation. The lessons learned documentation is a record that includes 1 ) a reference to the initiating report, 2) a reference to the associated corrective action plan, and 3) a summary of the lessons learned.

master document. A master document is the current official version of a document, stored and maintained by the document manager, from which controlled copies are created and distributed.

nonconformance. A nonconformance is a deficiency identified in an item.

nonconformance report. A nonconformance report is a record that characterizes a nonconformance. A nonconformance report includes 1) information that identifies the subject item, 2) a description of the nonconformance, 3) a reference to the governing inspection or test plan and associated procedures, and 4 ) the name of the verifier.

observation. An observation is documentation of a condition to which an assessor wants to call attention, although it fully complies with requirements. The contents of an observation include 1) the identifier of the associated assessment plan, 2) the date of the assessment, 3) the name and identifier of the item, program, process, system, or facility against which the observation is logged, 4) a description of the condition, and 5) the name of the assessor that logged the observation.

personnel-qualification documentation. Personnel-qualification documentation consists of records that document an individual's professional qualifications. This documentation includes the individual's 1) name, 2) education, 3) experience, 4) professional certifications, and 5) formal training.

plan. See program plan.

primary metrics. Primary metrics are measurements and analyses that must be used to evaluate the performance of a management program at regular intervals during its active life.

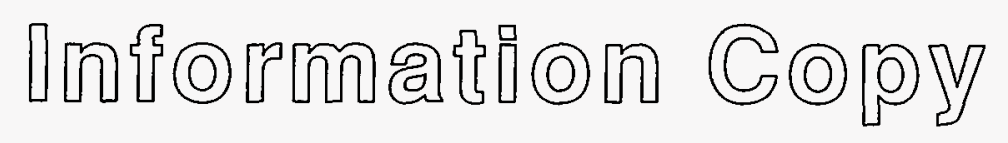




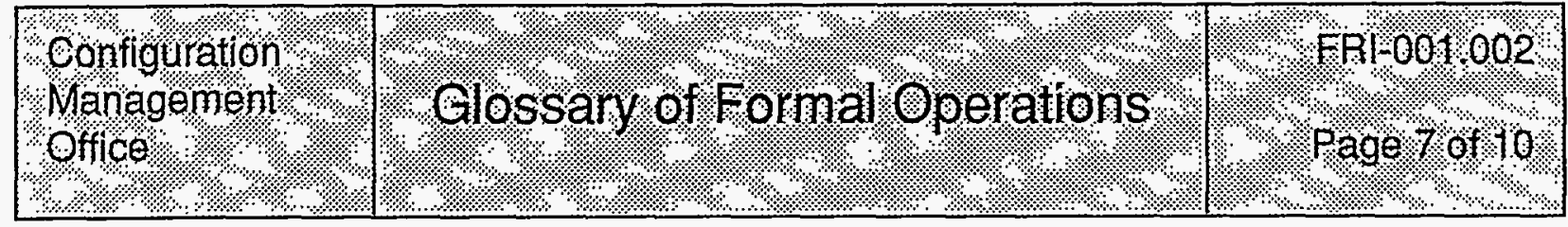

procedure. A procedure is a document that specifies the steps necessary to execute a work process. A procedure includes 1) the purpose of the procedure, 2) the procedure's scope, 3) a reference to the governing plan, 4) definitions, 5) a description of special hazards, conditions, limitations, and precautions, 6) worker qualification criteria, 7) training requirements, 8) roles and responsibilities, 9) procedural steps, and 10) required records.

procurement authority. A procurement authority is an individual or work function that performs a procurement process and maintains procurement records.

procurement documentation. Procurement documentation is a collection of records that includes 1) the authorized procurement request, 2) information relevant to the selection of a supplier, 3) contractual information, 4) supplier-provided information, 5) receipt and acceptance information, and 6) related correspondence.

procurement request. A procurement request is a record that is submitted to the procurement authority to request procurement of items or services. A procurement request includes 1) the procurement specification (requirements), 2) the acceptance plan, 3) any special instructions necessary for processing the procurement, and 4) formal notification to the procurement authority to initiate the procurement.

procurement requester. A procurement requester is an individual or work function that originates a procurement request to satisfy an identified need for items or services.

procurement specification. A procurement specification is a record that specifies the requirements for items or services to be procured. A procurement specification includes 1) descriptions of the items or services to be procured, 2) required performance criteria, 3) required physical or environmental parameters, 4) required certifications, and 5) delivery or performance time constraints.

proficiency test documentation. Proficiency test documentation is a record that documents a trainee's proficiency in the subject matter covered by a specific training course. A trainee's proficiency test documentation includes 1) the trainee's name, 2) the title and identifier of the training course, 3) the completed proficiency test, and 4) the test score.

program owner. A program owner is an individual or work function that mandates creation of a program and ensures that a formal plan is developed to describe the program.

program plan. A program plan is a document that includes the program's 1) purpose, 2) scope, 3) requirements, 4) organization and responsibilities, 5) budget, 6) schedule, 7) performance metrics, and 8) references. A program plan addresses the following programcontext elements: 1) the mission and goals of the program, 2) known risks and any mitigating factors, 3) known criteria against which the program will be judged, and 4) all explicit requirements that the program must satisfy.

proposed baseline. A proposed baseline is a collection of controlled elements that is under consideration by a configuration control board for certification.

qualification certification. A qualification certification is a record that certifies that an individual is qualified to perform a specific work process for a specified period of time. A

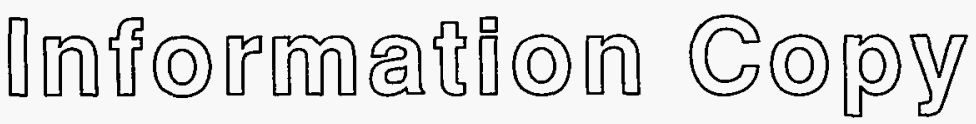




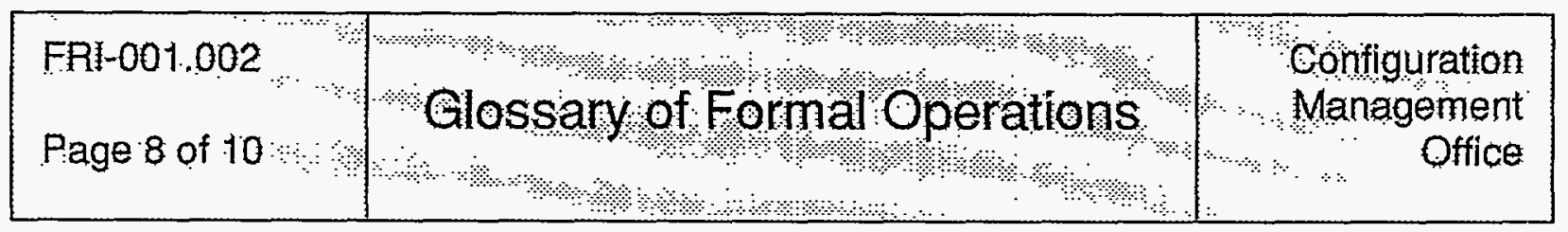

qualification certification includes 1) the individual's name, 2) the title and identifier of the subject work process, and 3) the qualification's expiration date.

qualification criteria. Qualification criteria are the minimum qualifications required of an individual to perform a specific work process as specified by the governing procedure.

record. A record is a document that preserves knowledge of events or facts relating to a program, process, system, or facility. A record consists of the following elements: 1) the record-generation date, 2) a unique identifier, 3) record-specific contents, and

4) authentication(s).

record of receipt. A record of receipt is a record that documents the receipt of items or services. A record of receipt includes 1) a list of the services rendered or the received items and associated quantities and 2) authentication by the procurement requester.

record request. A record request is a record that is submitted to a records manager to request the release of a record from the records repository. A record request includes 1) the date of the request, 2 ) the record identifier, and 3 ) the name of the requester.

records catalog. A records catalog is a register of all records maintained in a records repository.

records management standards. Records management standards are requirements that specify the distinct record types supported, security and protection requirements, retrievability criteria, minimum storage lifetime, and disposal criteria for each record type. Records management standards are specified in a document.

records manager. A records manager is an individual or work function responsible for admitting, maintaining, and releasing records within the records management environment.

report request. A report request is a record that requests the generation of a configuration status report. A report request includes 1) the requester's name, 2) an indication of urgency, 3 ) the report title, 4) a description of the report's content and format, 5) a recommended distribution list, and 6) the report-generation schedule.

report requester. A report requester is an individual or work function that is authorized to submit a report request to the configuration management liaison.

test plan. A test plan is a program plan that includes 1) the purpose of the test, 2) the items to be tested, 3) testing criteria, 4) a description of sampling methodologies to be used,5) a description of special test configurations, and 6) applicable calibration criteria.

trainee. A trainee is an individual identified by a work process owner who must receive specific training to meet the qualification criteria for a work process.

trainer. A trainer is an individual or work function designated and authorized by a work process owner to administer a training course.

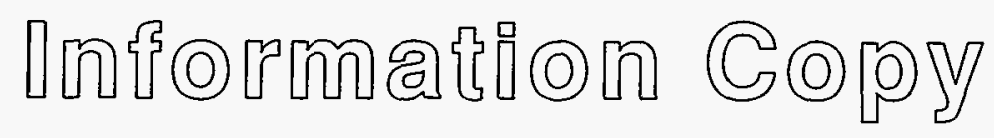




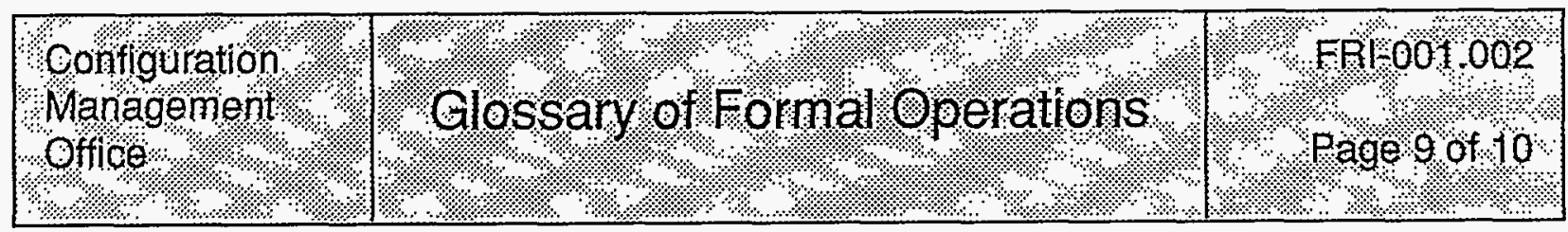

training certification. A training certification is a record that documents a trainee's successful completion of a training course. A training certification includes 1) the name of the trainee, 2) the title and identifier of the training course, and 3) the certification expiration date.

training course. A training course is a set of materials used by a trainer to provide instruction in, and testing for, a specific subject matter. A training course includes 1) a unique course identifier, 2) the course title, 3) a description of the intended audience, 4) learning objectives, 5) instruction guidelines, 6) trainer-qualification criteria, 7) presentation materials, 8) course notes, and 9) a proficiency test.

training course developer. A training course developer is an individual or work function designated by a work process owner to be responsible for creating a training course.

training plan. A training plan is a program plan that describes how an organization will develop and conduct its training program.

training program. A training program consists of a training plan and training courses.

validation. Validation is the act of determining if an item, process, service, or document is technically correct, reasonable, and appropriate.

variance. A variance is a temporary exception to a documented provision of a management program or its implementation.

variance request. A variance request is a record that characterizes a proposed variance. $A$ variance request includes 1 ) the name of the variance requester; 2 ) a reference to the provision against which the variance is requested; 3 ) a description of the requested variance, including its application limits; 4 ) a specification of the period of time during which the variance is valid;5) an indication of urgency; 6) justification for the variance; and 7) the configurationidentification labels and descriptions of all affected controlled elements.

variance request documentation. Variance request documentation is a record that includes the analyzed variance request, documentation from the configuration control board's analysis of the variance request, disposition of the analyzed variance request, and the configuration control board authentication.

variance requester. A variance requester is an individual or work function that submits a variance request.

verification. Verification is the act of determining if an item, process, service, or document is in full compliance with its requirements.

verifier. A verifier is an individual or work function responsible for performing an inspection or test.

work authorization. A work authorization is a record that authorizes a change agent to implement a change specified in an approved change request. A work authorization includes 1) the name of the affected baseline, 2) the name of the change agent, 3) a list of associated

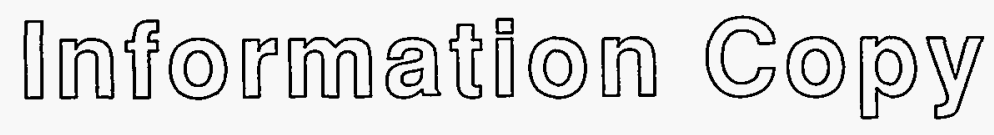




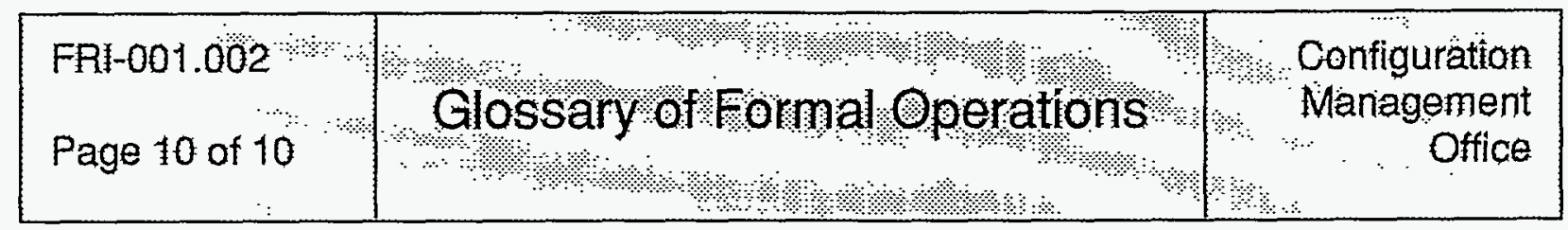

change requests, and 4) the implementation information including instructions, constraints, required resources, and schedule.

work function. A work function is an individual or organization that has a defined set of responsibilities with respect to performing a specific work process.

work process. A work process is a series of actions or steps that are performed to accomplish a task.

work process owner. A work process owner is the individual or work function accountable for the conduct of a work process.

\subsection{REFERENCES}

1. ASME NQA-1-1989, Quality Assurance Program Requirements for Nuclear Facilities.

2. Bersoff, E. H., V. D. Henderson, and S. G. Siegel, Software Configuration Management. Englewood Cliffs, N.J.: Prentice-Hall, Inc., 1980.

3. DOE Order 1324.5A, Records Management Program.

4. DOE Order 4330.4A, Maintenance Management Program.

5. DOE Order 4700.1, Project Management System.

6. DOE Order 5000.3B, Occurrence Reporting and Processing of Operations Information.

7. DOE Order 5480.5, Safety of Nuclear Facilities.

8. DOE Order 5480.19, Conduct of Operations Requirements for DOE Facilities.

9. DOE Order 5480.20, Personnel Selection, Qualification, Training, and Staffing Requirements at DOE Reactor and Non-Reactor Nuclear Facilities.

10. DOE Order 5480.23, Nuclear Safety Analysis Reports.

11. DOE Order 5700.6C, Quality Assurance.

12. LANL-YMP-QP-17.4, Records Preparation.

13. LANL-YMP-QP-18.1, Audits.

\subsection{ATTACHMENTS}

Attachment 1, Document Improvement Questionnaire

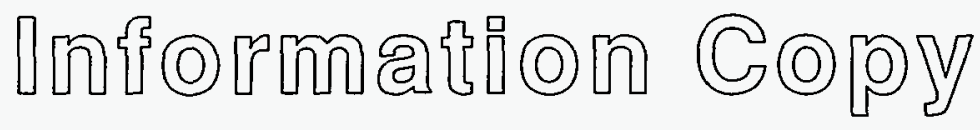




\section{DOCUMENT IMPROVEMENT QUESTIONNAIRE}

\begin{tabular}{|c|c|c|c|c|c|}
\hline & Excellent & Good & Fair & Poor & $\mathrm{N} / \mathrm{A}$ \\
\hline Accuracy & $\square$ & $\square$ & $\square$ & $\square$ & $\square$ \\
\hline Clarity & $\square$ & $\square$ & $\square$ & $\square$ & $\square$ \\
\hline Consistency & $\square$ & $\square$ & $\square$ & $\square$ & $\square$ \\
\hline Completeness & $\square$ & $\square$ & $\square$ & $\square$ & $\square$ \\
\hline Level of Detail & $\square$ & $\square$ & $\square$ & $\square$ & $\square$ \\
\hline Organization & $\square$ & $\square$ & $\square$ & $\square$ & $\square$ \\
\hline Relevance & $\square$ & $\square$ & $\square$ & $\square$ & $\square$ \\
\hline Usefulness & $\square$ & $\square$ & $\square$ & $\square$ & $\square$ \\
\hline Understandability & $\square$ & $\square$ & $\square$ & $\square$ & $\square$ \\
\hline Examples & $\square$ & $\square$ & $\square$ & $\square$ & $\square$ \\
\hline Figures & $\square$ & $\square$ & $\square$ & $\square$ & $\square$ \\
\hline Index & $\square$ & $\square$ & $\square$ & $\square$ & $\square$ \\
\hline Lack of Editorial Errors & $\square$ & $\square$ & $\square$ & $\square$ & $\square$ \\
\hline Page Layout & $\square$ & $\square$ & $\square$ & $\square$ & $\square$ \\
\hline Overall Quality & $\square$ & $\square$ & $\square$ & $\square$ & $\square$ \\
\hline
\end{tabular}

The best feature of this document is

The worst feature of this document is

I found the following errors in this document:

Page Description

Additional comments or suggestions to improve this document:

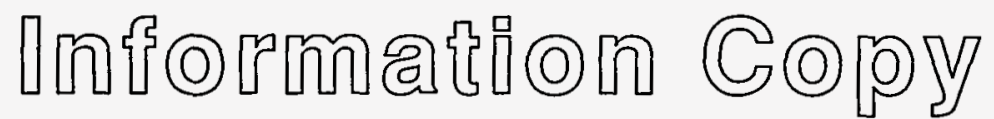

\begin{tabular}{|l|l|l|l|l|}
\hline Name (Optional) & Organization & Telephone & Mail Stop & Percent of Document Read \\
\hline
\end{tabular}

